\title{
Face vs. empathy: the social foundation of Maithili verb agreement*
}

\author{
BALTHASAR BICKEL, WALTER BISANG, and YOGENDRA P. YĀDAVA
}

\begin{abstract}
Maithili features one of the most complex agreement systems of any IndoAryan language. Not only nominative and non-nominative subjects, but also objects, other core arguments, and even nonarguments are cross-referenced, allowing for a maximum of three participants encoded by the verb desinences. The categories reflected in the morphology are person, honorific degree, and, in the case of third persons, gender, spatial distance, and focus. However, not all combinations of category choices are equally represented, and there are many cases of neutralization. We demonstrate that the paradigm structure of Maithili verb agreement is not arbitrary but can be predicted by two general principles of interaction in Maithil society: a principle of social hierarchy underlying the evaluation of people's "face" (Brown and Levinson 1987 [1978]), and a principle of social solidarity defining degrees of "empathy" (Kuno 1987) to which people identify with others. Maithili verb agreement not only reflects a specific style of social cognition but also constitutes a prime means of maintaining this style by requiring constant attention to its defining parameters. In line with this, we find that the system is partly reduced by uneducated, so-called lower-caste speakers, who are least interested in maintaining this style, especially its emphasis on hierarchy.
\end{abstract}

\section{Introduction}

One of the main tenets of functional linguistics is that grammar makes up only a relatively small part of linguistic complexity and that many putative rules of grammar can be effectively reduced to pragmatic and cognitive principles. Recent research has shown that this holds not only for relatively simple rules but also for more intricate rule systems such as the rules of reflexive and pronoun binding, which have been partially 
reduced to Gricean maxims (Levinson 1987, 1991) or the grammar of extraction constraints, which has been largely reduced to issues of focus structure (Van Valin 1995).

In this paper we put forward another case in which a highly complex rule system turns out to be far from arbitrary but is in significant parts reducible to principles of human interaction that are by no means specific to language: principles of social hierarchy underlying the subtle evaluation of people's "face" (Brown and Levinson 1987 [1978]) and principles of social solidarity underlying the degrees of "empathy" to which people identify with others (Kuno 1987). The rule system we are concerned with is verb agreement in Maithili, an Indo-Aryan language spoken by about 30 million people in the Indian state of Bihār and the Nepalese Tarāī region (Grierson 1909; Williams 1973; Stump and Yadav 1988; Yadav 1996; Yadava 1996). Our data are based on the dialect of Maithili spoken in the Siraha district in Nepal's Sagarmāthā zone.

The Maithili verb cross-references not only subjects (nominative NPs), but also objects, other core arguments, and even nonarguments, allowing for a maximum of three participants encoded by the verb desinences. The categories reflected in the morphology are person (first, second, third), honorific degree (nonhonorific, mid-honorific, high-honorific) and, in the case of third persons only, spatial distance (proximate vs. remote) and focus (in focus vs. out of focus). The following examples show single, (1a), double, (1b), and triple, (1c), argument agreement: ${ }^{1}$

(1) a. tũ daur-1-æ.

$2 \mathrm{nhN}$ run-PT-2nhN

'You ${ }^{\text {nh }}$ ran.'

b. tũ ekrā dekh-1-ah-ik.

2nhN 3proxDAT see-PT-2nh/mhN-3proxNN

'You ${ }^{\text {nh }}$ saw him ${ }^{\text {nh }}$ (who is here).'

c. ham torā kaniyā-kẽ

$1 \mathrm{~N} \quad 2 \mathrm{nh} / \mathrm{mhDAT}$ bride-DAT

dekh-au-l-i-au-nh.

see-CAUS-PT-1N-2nh/mhNN-3hNN

'I showed $\mathrm{you}^{\mathrm{nh} / \mathrm{mh}}$ the bride ${ }^{\mathrm{h}}$.'

Possible controllers of verb agreement are not only the arguments of a predicate but also nonarguments like nominals in postpositional phrases, (2a), and possessors therein, (2b), as well as deictic referents in the discourse context, $(2 \mathrm{c}):^{2}$

(2) a. tõ hunkā lel kāj kae-1-ah-unh. $2 \mathrm{mhN} 3 \mathrm{hOBL}$ for work do-PT-2nh/mhN-3hNN

'You ${ }^{\mathrm{mh}}$ worked for him ${ }^{\mathrm{h}}$.' 
b. ham tohar ghar par ge-1 ch-al-i-ah.

1N 2nh/mhGEN house LOC go-P AUX-PT-1N-2mhNN

'I had been to your ${ }^{\mathrm{mh}}$ house.'

c. ham okrā mār-1-i-ah.

1N 2nh.remDAT beat-PT-1N-2mhNN

'I beat him $^{\text {nh }}$ (who is related to you ${ }^{\mathrm{mh}}$, etc.).'

One of the major challenges in describing this morphology comes from the fact that agreement is not uniform across persons and honorific degrees. For instance, while there is a clear-cut distinction between forms with a first-person, (3a), and a second-person nonhonorific subject, (3b), this distinction is blurred when it comes to a second person of honorific status, (3c):

(3) a. ham daur-1-aũh.

$1 \mathrm{~N}$ run-PT- $1 / 2 \mathrm{hN}$

'I ran.'

b. tũ daur-1-æ.

$2 \mathrm{nhN}$ run-PT-2nhN

'You' ${ }^{\text {nh }}$ ran.'

c. ahã daur-1-aũh.

$2 \mathrm{hN}$ run-PT- $1 / 2 \mathrm{hN}$

'You' ran.'

With double agreement, the patterns of neutralization are more complex. With transitive verbs, for example, some forms register both subject and object, in others it is only the subject that triggers verb agreement. The distribution cross-cuts person and honorificity distinctions in complex ways so that, for instance, an honorific third-person object is as good an agreement trigger, (4a), as a nonhonorific second person, (4b), whereas a high-honorific second-person object remains unmarked as much as a first person or a nonhonorific third person, (4c).

(4) a. u hunkā dekh-al-k-ainh.

3nh.remN 3h.remDAT see-PT-3N-3hNN

'S/he ${ }^{\text {nh }}$ saw him/her'.'

b. u torā dekh-al-k-auk.

3nh.remN 2nh/mhDAT see-PT-3N-2nhNN

'S/he ${ }^{\text {nh }}$ saw you ${ }^{\text {nh }}$ '

c. u ahãkẽ/hamrā/okrā dekh-l-ak.

3nh.remN 2hDAT/1DAT/3nh.remDAT see-PT-3N

'S/he ${ }^{\text {nh }}$ saw you'h $/$ me $/$ him $^{\text {nh }}$.'

The goal of this paper is to explain why person marking is not uniform and to predict which scenario distinctions are formally neutralized in 
particular forms. In section 2 we describe and analyze the verb paradigms of Maithili and in section 3 we propose two pragmatic constraints, FACE and EMPATHY, which predict the distribution of person marking in detailed ways. In the concluding section, we make some suggestions as to how the constraints discussed relate to fundamental structures in Maithil society and how these could be responsible for the historical development and the current maintenance of the system.

\section{The structure of Maithili verb agreement}

As in other Indo-Aryan languages, the Maithili verb paradigm is polymorphemic and is formed by participles followed by inflected auxiliaries. All morphological elements normally follow the verb stem (cf. Masica 1991: 257). The following rule captures the general structure of Maithili verb forms (cf. Yadava 1996).

(5) $\mathrm{V} \rightarrow$ Stem(-Aspect)(Aspectual Aux) (Aux)-Tense-Agr1 (-Agr2-Agr3)

As noted in the introduction, Maithili allows for multiple verb agreement (labeled here as Agr1 through Agr3), and in this respect the language is quite different from most other Indo-Aryan languages. ${ }^{3}$ The basic structure with multiple auxiliaries is illustrated in the following sentence:

(6) Hari-ji daur-ait rah-ait ch-al-āh.

Hari-h run-IP AUX-I AUX-PT-3hN

'Hari had been running.'

Together with the imperfective participial (IP) form daurait 'running', the auxiliary rah- encodes imperfective aspect and functions itself as a complement of the past-tense indicating auxiliary chalāh 'he ${ }^{\mathrm{h}}$ was'. This creates an imperfective 'past-in-the-past' reading (which the English translation neutralizes with the past perfect). Only the last auxiliary in a sequence is inflected for person, case, and honorific degree.

The rule in (5) shows one systematic exception in forms expressing present tense. In these forms, which draw on the imperfective participle and a ch- auxiliary, nonhonorific third-person agreement markers are prefixed, (7a), rather than suffixed to the main auxiliary as would be the case with other agreement markers, (7b):

(7) a. u daur-ait ai-ch.

3nh.remN run-IP 3-AUX

' $\mathrm{S} / \mathrm{he}^{\mathrm{nh}}$ is running.'

b. o daur-ait ch-aith.

3h.remN run-IP AUX-3hN

' $\mathrm{S} / \mathrm{he}^{\mathrm{h}}$ is running.' 
In the remainder of this section we first present and analyze the complete paradigms of verb agreement, taking note of both morphophonological and semantic regularities (section 2.1). In section 2.2 we further introduce the structure of single and multiple verb agreement, especially focusing on the distinction between nominative (abbreviated as $\mathrm{N}$ ) and non-nominative (NN) agreement. Section 2.3 briefly compares the features of verb agreement with honorificity and case marking in pronouns and other nominals.

\subsection{Paradigms and morpheme analysis}

Table 1 summarizes the single and double agreement paradigms in Maithili; a sample paradigm is reproduced in the Appendix. In Table 1 we do not include triple agreement, since it allows only for one single form in -i-au-nh, marking a first person $(-i)$, a non- or mid-honorific second person (-au), and an honorific third person (-nh) (see example [1c] in the introduction for illustration and section 2.6 below for discussion). The agreement desinences are generally distinct for future (fut.) and nonfuture (nonf.) tense forms, but in some cases there are specific desinences that occur only in verbs inflected for past tense. The paradigm template in the table is organized according to the traditional principle that those person combinations or "scenarios" are neighbors that can formally converge (cf. Plank 1991), rather than according to any "etic" assumption about person hierarchy (but see the Appendix for such an arrangement). Formally neutralized scenarios are demarkated by a line and the individual desinences are meant to apply to all scenarios within the borders imposed by such a line: $-i$, for example, applies to the nominative single-argument first- and honorific second-person scenarios as well as to the $1 \rightarrow 2 \mathrm{~h}$ and $2 \mathrm{~h} \rightarrow 1$ scenarios of double-agreement forms. The shaded areas stand for logical and structural gaps in the paradigm: within one and the same event, first- and second-person referents cannot combine with different first- and second-person referents, respectively, and if the referents are identical, the use of reflexive pronouns and single verb agreement is mandatory. The only logically possible situation of two distinct first persons would be one in which one person is understood as singular and the other as plural ('I will make us some tea'), but - as in some other languages with multiple agreement (Addis 1993: 432; Bickel 1995: 102f.) - there simply is no Maithili form that expresses such a scenario.

Agreement in single-argument (intransitive) clauses shows a binary contrast of nominative and non-nominative cases. Forms with only a 


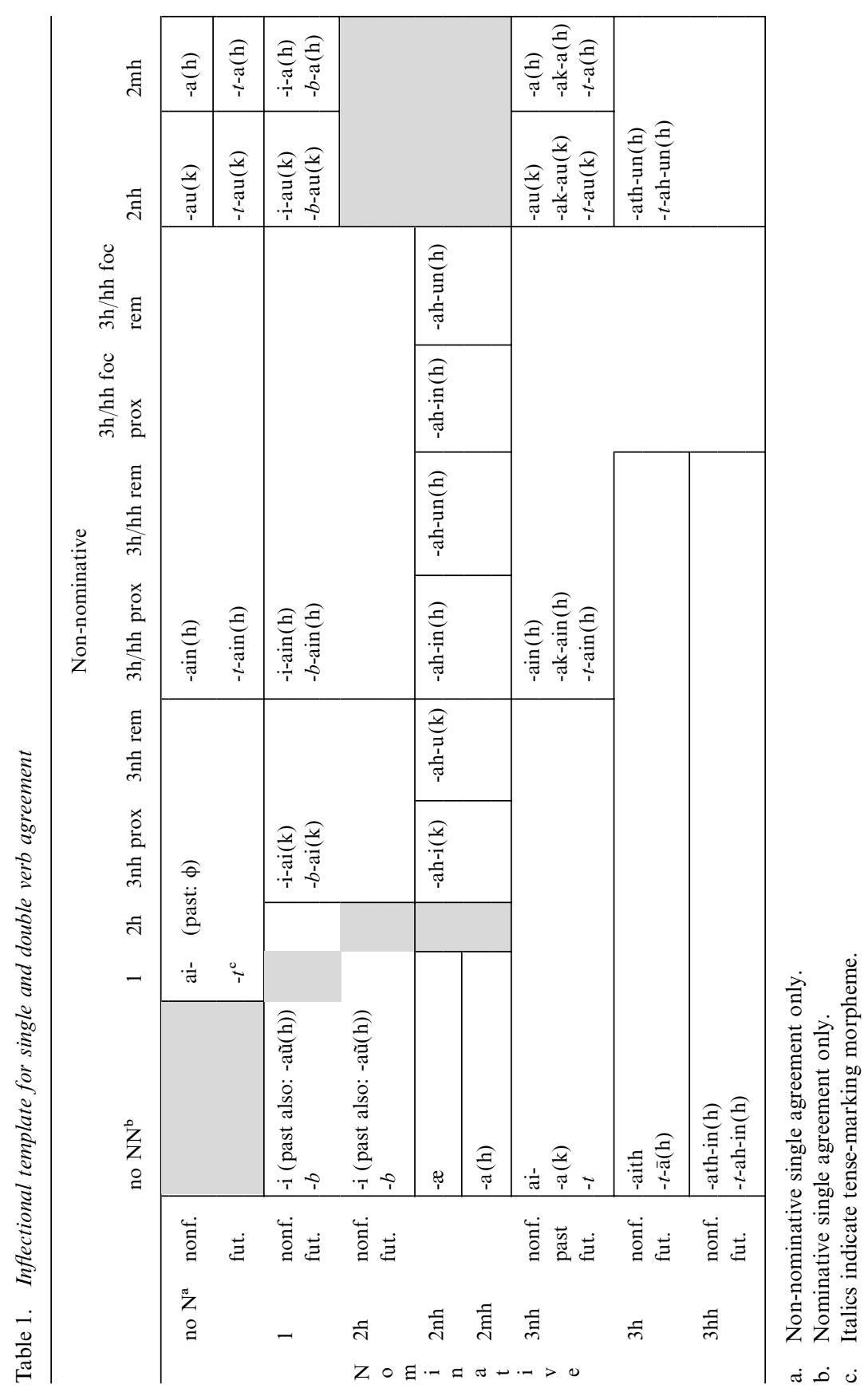


nominative argument, but no non-nominative argument (indicated by "no NN") are listed vertically on the leftmost side; forms with only nonnominative agreement ("no N") are listed horizontally on the top line. The rest of the table consists of double agreement with both nominative and non-nominative referents.

In highly formal speech, agreement distinguishes feminine gender with honorific third persons in past and future forms. For this purpose, $-i h$ is used instead of -aith (nonfuture) and -ah (future) (cf. Yadav 1996: 64):

$$
\begin{aligned}
& \text { o daur-1-ih / daur-t-ih. } \\
& \text { 3h.remN run-NFUT-3hN:FEM run-FUT[3]-3hN:FEM } \\
& \text { 'She }{ }^{\text {h }} \text { ran / will run.' }
\end{aligned}
$$

These special forms are not included in Table 1, and we will ignore them in the remainder.

A morpheme analysis of Table 1 yields the list of individual agreement morphemes with their associated meanings given in Table 2. In this table, elements in square brackets indicate selectional restrictions of morphemes. Final $-k$ and $-h$ are optional elements, usually pronounced only in very careful, educated speech. Their occurrence is limited to wordfinal position in any event.

Most of Maithili allomorphy is due to prosodic structure. For instance, tautosyllabic consonant clusters are often broken up by epenthesis of a

Table 2. Overview of person marking in the Maithili verb

\begin{tabular}{ll}
\hline $\begin{array}{l}\text { Agreement } \\
\text { morpheme }\end{array}$ & Meaning \\
\hline$-i$ & $1 / 2 \mathrm{~h}$ nominative [present or past] \\
$-a \tilde{u}(h)$ & $1 / 2 \mathrm{~h}$ nominative [past] \\
$-a$ & $2 \mathrm{nh}$ nominative \\
$-a(h)$ & $2 \mathrm{mh}$ or $2 \mathrm{nh} / \mathrm{mh}$ if combined with third person non-nominative \\
$-a i(k) \sim a i-$ & 3 or dummy agreement in present non-nominative intransitive \\
$-a(k) \sim-k \sim \phi$ & forms \\
$-a i t h \sim-a t h$ & 3 nominative \\
$-\bar{a}(h) \sim-a(h)$ & $3 \mathrm{~h}$ nominative \\
$-i(k)$ & $3 \mathrm{~h}$ nominative [future] \\
$-u(k)$ & $3 \mathrm{nh}$ proximate non-nominative $[2 \mathrm{nh} / \mathrm{mh} \rightarrow]$ \\
$-i n(h)$ & $3 \mathrm{nh}$ remote non-nominative $[2 \mathrm{nh} / \mathrm{mh} \rightarrow]$ \\
$-u n(h)$ & $3 \mathrm{~h} / \mathrm{hh}$ proximate \\
$-a i n(h) \sim-n h$ & $2 \mathrm{nh} /$ mh $\leftrightarrow 3 \mathrm{~h} / \mathrm{hh}$ \\
$-a u(k)$ & $3 \mathrm{~h} / \mathrm{hh}$ non-nominative \\
$-t \sim-b[$ if nom. $=1 / 2]$ & $2 \mathrm{nh}$ non-nominative or $2 \mathrm{nh} / \mathrm{mh}$ non-nominative in triple \\
\hline
\end{tabular}


short /a/ (realized as schwa; see note 1); as in ch-l-āh [AUX-PT-3hN] from example (6) above, which is realized as chalāh. Where /a/ epenthesis leads to resyllabification, stem syllables usually undergo compensatory lengthening, as in lag-l- $\phi \rightarrow l a . g a l \rightarrow l \overline{\text { aggal }}$ 'was felt'. Prosody is also pertinent for the -aith $\sim$-ath and $-\bar{a} h \sim-a h$ alternations. Main stress falls on the last syllable in verb forms and there is a general constraint of pretonic shortness, first identified by Jha (1940: 457), which requires pretonic syllables to be light, that is, short-vowelled and open. This constraint selects -ath and -ah over -aith and - $\bar{h}$, respectively, if they appear in penultimate, that is, pretonic position. Another effect is that the sociolectal alternation between the ' $1 / 2 \mathrm{~h}$ nominative' forms -aũh (high-caste speech) and $-i$ (low-caste speech) is neutralized in pretonic position to $-i$ : compare for example dekh-l-i-áik 'I saw him ${ }^{\text {nh }}$, , vs. *dekhliaũháik, which violates the pretonic shortness constraint. Yet another effect of the pretonic shortness constraint is the neutralization of the nominative nonhonorific $(-\infty)$ and mid-honorific (-ah) second-person markers when they are combined with a third-person agreement morpheme: $-\infty$, being historically derived from the diphthong $-a i$, is substituted by short $-a h$ throughout. A final effect of the pretonic shortness constraint to be noted here is that in the third slot of agreement markers (Agr3 in [5] and in Table 2), the honorific/high-honorific third-person suffix -ainh is shortened to an extrametrical single consonant, $-n h$. The full form -ainh would violate the pretonic shortness constraint, since the preceding morpheme in Agr2 (-au) is long and cannot be substituted by a short allomorph.

Notice that a side-effect of the -ainh $\sim-n h$ allomorphy is that Maithili person desinences are never longer than two syllables. This is the other general prosodic constraint on the conjugational system and rules out other triple agreement forms that would appear logically possible from Table 2. Triple agreement is, as noted before, limited to the single combination -i-au-nh ' $1 \mathrm{~N}-2 \mathrm{nh} / \mathrm{mhNN}-3 \mathrm{hNN}$ '. All other semantically conceivable forms are ill-formed prosodically because they comprise more than two syllables $\left({ }^{*}\right.$-ahikunh ' $2 \mathrm{mhN}-3 \mathrm{nh}$.proxNN-3hNN', *-ahinhunh '2mhN-3h.proxN-3hNN', *-akainhinh '3nhN-3hNN-3h.proxNN' etc.). ${ }^{4}$

Two allomorphies in the paradigms are lexically governed. First, the honorific third-person marker in past forms is - a h instead of -aith with some verbs such as $j \bar{a}$ - 'go', which inflects (with stem suppletion) as ge-l-ăh 'he ${ }^{\mathrm{h}}$ went.' Second, some verbs require zero agreement instead of $-a k$ in nonhonorific third-person past forms: for example, again from $j \bar{a}$-, gel- $\phi$ 'he ${ }^{\text {nh }}$ went', or pa $k a l-\phi$ 'it is ripe/cooked' from $p \bar{a} k$ - 'to ripen, get cooked' with /a/-epenthesis breaking up the final $/ \mathrm{kl} /$ cluster. Apart from these functions, zero agreement, that is, auxiliaries or stems marked by tense only, is limited to cases of "dummy" agreement markers in some 
forms with exclusive non-nominative agreement (see the top row in Table 1). Such forms are typical in so-called "dative subject" expressions as illustrated in (9a). In other tenses, (9b), dummy agreement is overtly marked (but glossed throughout as $\phi$ )

(9) a. hamrā bhukh lāga-1 $[<$ lāg-1- $\phi]$.

1DAT hunger be(come)perceptible-PT- $\phi$

'I got hungry.'

b. hamrā bhukh lāgait ai-ch.

1DAT hunger be(come) perceptible-IP $\phi$-AUX

'I am getting hungry.'

Apart from the past-tense forms, dummy non-nominative agreement is largely identical to the nominative agreement forms for nonhonorific third person, that is, with $a i$ (nonfuture), $-a k$ (past), or $-t$ (future) (see the first column in Table 1). Thus, dummy agreement probably results historically from impersonally used nominative third-person forms. This is further corroborated by the observation that the future tense marker appears in the $-t$ variant, which is reserved elsewhere for the third person (see below). Synchronically, however, dummy-agreement forms function exclusively as regular substitutes for non-nominative agreement with first, honorific second, or nonhonorific third persons.

A final case of allomorphy to be noted is that the morpheme $a i$ is prefixed if it is the only agreement marker, (10a) and (10b), but suffixed if it combines with other person or honorific degree markers, $(10 \mathrm{c})$. Notice that this is irrespective of its function as a (nonhonorific) third person marker, (10a) and (10c), or as a dummy-agreement marker, (10b):
a. $u$
daur-ait ai-ch. $\quad(=[7 \mathrm{a}])$
3nh.remN run-IP 3-AUX
' $\mathrm{S} / \mathrm{h} \mathrm{h}^{\mathrm{nh}}$ is running.'
b. ahã̃kẽ hãs-ā-it
ai-ch.
2hDAT laugh-INVOL-IP $\phi$-AUX
'Laughing comes naturally to you.'
c. ahã okrā dekh-ait ch-i-ai.
$2 \mathrm{hN} 3 \mathrm{nh} . \mathrm{remDAT}$ see-IP AUX-2hN-3
'You ${ }^{\text {h }}$ see him $/$ her $^{\text {nh }}$.'

In many parts of the paradigm, agreement interacts with tense marking. First, there are several morphemes restricted to specific tenses, which is indicated by square brackets in Table 2. The first-person marker -aũh, for instance, is limited to past tense forms, which are marked by -l. Other tenses encode the same person by $a i$ (present) or $-a$ (future). Other agreement suffixes, such as the nonhonorific and mid-honorific second- 
person markers, are uniform across tenses. Second, future-tense marking varies according to person: the category is realized by $-b$ with the first and second persons but by $-t$ with the third person. This difference is probably motivated by the fact that from the point of view of the speaker, speech-act participants form a distinct category in so far as they have a more direct control over future events than third persons. The personbased allomorphy of $-b \sim-t$ makes it possible that the marker functionally substitutes in some cases for agreement (and it is for this reason that we include it in the paradigm overview in Table 1). In this case, $-b$ signals a first or second person whereas $-t$ marks third-person referents:

(11) a. dekh-b-ainh. see-FUT[1/2]-3hNN

'I/you ${ }^{\mathrm{h}}$ will see him/her ${ }^{\mathrm{h}}$.'

b. dekh-t-ainh.

see-FUT[3]-3hNN

'S/hen wh will see him/her' ${ }^{\text {h }}$ '

With regard to the semantic structure of the morphemes in Table 2, it should be noted that not all morphemes are equally specialized in function. Next to highly specific morphemes such as -unh, which exclusively mark a $2 \mathrm{nh} / \mathrm{mh} \leftrightarrow 3 \mathrm{~h} / \mathrm{hh}$ scenario, that is, a situation where a non- or mid-honorific second person and an honorific or high-honorific third person are simultaneously involved, there are extremely general markers such as the third-person markers $a i$ ' 3 ' or $-a(k) \sim-k$ ' $3 \mathrm{~N}$ '. Opposition to more specific markers, however, induces more specialized readings. Thus, in example (12a), ai must be understood as a marker of nonhonorific degree, because honorific reference is preempted by the more specific desinences -aith, (12a), and -athinh, (12b):

(12) a. paṛh-ait ai-ch.

read-IP 3-AUX

' $\mathrm{S} / \mathrm{he} \mathrm{h}^{\mathrm{nh}}$ is reading.'

b. parh-ait ch-aith.

read-IP AUX-3hN

' $\mathrm{S} / \mathrm{he}^{\mathrm{h}}$ is reading.'

c. parh-ait ch-ath-inh.

read-IP AUX-3hN-3h.prox

' $\mathrm{S} / \mathrm{he}^{\mathrm{hh}}$ is reading.'

In the same way, $-a(k) \sim-k$ receives a nonhonorific reading whenever it is in paradigmatic opposition to -aith (see also Table 1): 
(13) a. hunkā dekh-al-k-ainh.

3h.remDAT see-PT-3N-3hNN

'S/he ${ }^{\text {nh }}$ saw her/him ${ }^{\text {h }}$.'

b. hunkā dekh-1-aith.

3h.remDAT see-PT-3hN

'S/he ${ }^{\text {h }}$ saw her/him '.'

In other contexts, where there is no such contrast, the morphemes $a i$ and $-a(k) \sim-k$ maintain their neutral value on the honorificity scale. Indeed, they can even combine with honorific or even high-honorific reference. With $a i$, this is the case in periphrastic constructions used together with the pronoun apne as high-honorific second person forms, (14a). The desinence $-a(k) \sim-k$ can assume honorific reference in transitive forms with focussed objects like hunke in (14b):

$$
\begin{aligned}
& \text { a. apne parh-al jā-it ch-aik. } \\
& \text { 2hhN read-P HON.AUX-IP AUX-3 } \\
& \text { 'You' }{ }^{\text {hh }} \text { are reading.' }
\end{aligned}
$$

b. hunkē dekh-al-k-ainh 3h.remDAT:FOC see-PT-3N-3hNN 'He $\mathrm{He}^{\mathrm{nh}} / \mathrm{h}$ saw HIM ${ }^{\mathrm{h}}$.' ('It was him ${ }^{\mathrm{h}}$ who he ${ }^{\mathrm{h}}$ saw.')

Because of its periphrastic nature, this construction is not included in the paradigm in Table 1, but we discuss it further below in section 2.4.

With regard to morpheme structure, notice finally that the category of nominative high-honorific third person agreement as in (12c) is realized by the combination of two honorificity markers: -ath, the marker of honorific third persons in the nominative, and -inh, which elsewhere encodes proximate honorific or high-honorific referents in non-nominative function. We will see in section 3.1 that the use of a proximate marker here is functionally motivated.

\subsection{Nominative and non-nominative agreement}

As noted in the introduction, a Maithili verb can have single, double, and triple agreement. Agreement slot 1 (Agr1 in [5] above) is filled by elements from either of two sets of morphemes, viz. the nominative set or the non-nominative set. The other two slots, Agr2 and Agr3, are filled by non-nominative morphemes only, and if they are present, the Agr1 marker must be in the nominative.

Single agreement is listed in the first column (nominative) and the top row (non-nominative) of Table 1 . The controller of nominative agreement is always a (transitive or intransitive) subject in the nominative case: ${ }^{5}$ 
(15) a. o. daur-1-aith.

3h.remN run-PT-3hN

'He ${ }^{\mathrm{h}}$ ran.'

b. o kitāb nahi dekh-l-aith

3h.remN book not see-PT-3hN

'He ${ }^{\text {h }}$ didn't see the book.'

Elements of the non-nominative set of agreement affixes are triggered by controllers in non-nominative cases like dative, ablative, genitive, and locative. They are exemplified in (16a)-(16d), respectively:

a. hunkā cithi likh-ai-kẽ cha-l-ainh.

3h.remDAT letter write-IP-DAT be-PT-3hNN

'He had to write a letter.'

b. hunkā-sã i ghar ban-āo-1

3h.remOBL-ABL this house build-CAUS-P

ge-1-ainh.

PASS.AUX-PT-3hNN

'This house was built by $\operatorname{him}^{\mathrm{h}}$ (i.e. on his ${ }^{\mathrm{h}}$ demand).'

c. hunak paisā har-ā ge-1-ainh.

3h.remGEN money lose-INVOL PASS.AUX-PT-3hNN

'His ${ }^{\mathrm{h}}$ money got lost.'

d. hunkā-mẽ sāphe dayā nahi ch-ainh.

3h.remOBL-LOC at.all mercy not be-3hNN

' $\mathrm{He}^{\mathrm{h}}$ has no mercy at all.'

Furthermore, agreement is in the non-nominative case, too, if it refers to a deictic referent that is not overtly present in the sentence:

(17) barad bhāg-al jā-it ch-auk.

ox run-P go-IP AUX-2nhNN

'The ox (that belongs to you ${ }^{\text {nh }}$ ) is running away.'

This type of verb inflection will be discussed in detail in section 3.3.

A comparison of the non-nominative with the nominative paradigm reveals that except for mid-honorific second persons in nonfuture tenses and nonhonorific third persons in nonpast tenses, the non-nominative agreement affixes are different from nominative ones. This is made evident by the synopsis in Table 3 .

We have labeled the difference between the two sets of agreement markers "nominative" vs. "non-nominative." This begs the question of why we do not analyze the difference in terms of grammatical relations, that is, as a "subject" vs. "non-subject" distinction. There is a straightforward argument against this, discussed by Bickel and Yadava (1998), 
Table 3. Nominative and non-nominative single agreement

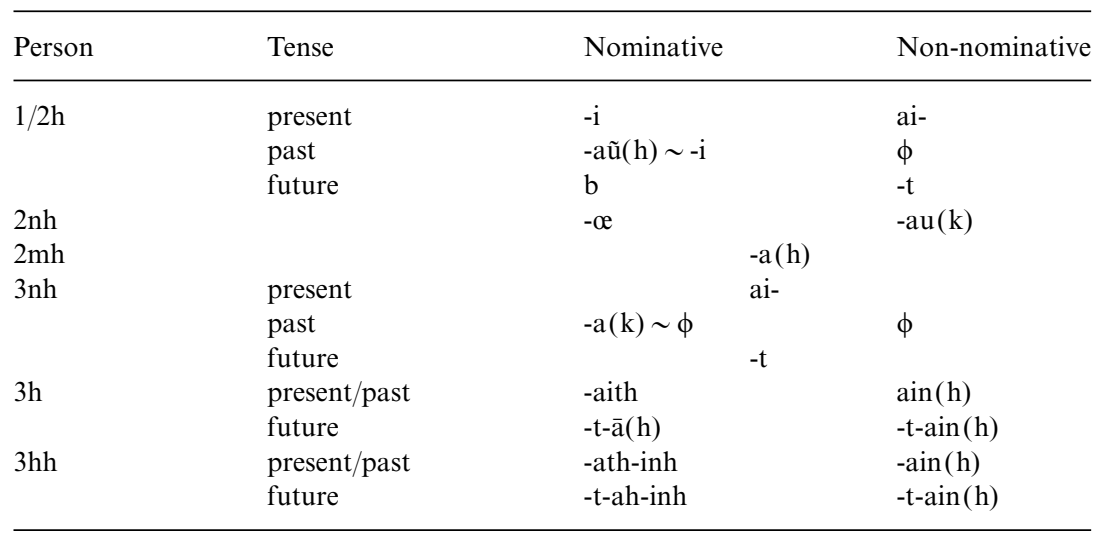

which we shall briefly present in the following. In single-argument (intransitive) forms, the distinction between nominative and non-nominative forms does not coincide with a distinction that could be analyzed in terms of semantic roles or grammatical relations. Specifically, the distinction cannot be reduced to a difference of control or agentivity as in a split-S or fluid-S system (Dixon 1994) nor to an unergative vs. nonunergative distinction that would have intransitive clauses with underlying subjects vs. underlying nonsubjects (or "initial 1" vs. "initial non-1" in relational grammar). The inflectional split in Maithili cross-cuts semantic roles and underlying grammatical relations (if any). Nominative agreement covers the most agentive participants ("underlying subjects") as much as the most patientive ones ("underlying objects"):
a. o cithī likh-l-aith.
3h.remN letter write-PT-3hN
'He wrote a letter.'
b. o khas-l-aith.
3h.remN fall-PT-3hN
'He fell.'

Likewise, non-nominative agreement can index patients ("underlying objects") as much as agents ("underlying" or "logical subjects"):

(19) a. u hunkā mār-l-ak-ainh.

3nh.remN 3h.remDAT hit-PT-3N-3hNN

'S/he ${ }^{\text {nh }}$ hit him/her'.'

b. hunkā-sã i cithī likh-al ge-l-ainh.

3h.remOBL-ABL this letter: $\mathrm{N}$ write-P PASS.AUX-PT-3hNN

'This letter was written by him.' 
The only systematic correlate of the inflectional split is the case frame that is used, and this does not, as we have just seen, necessarily correspond to a specific thematic argument structure. ${ }^{6}$

In double and triple agreement, the first agreement marker, Agr1, must be in nominative case, and the others in non-nominative. This is illustrated by the following examples:

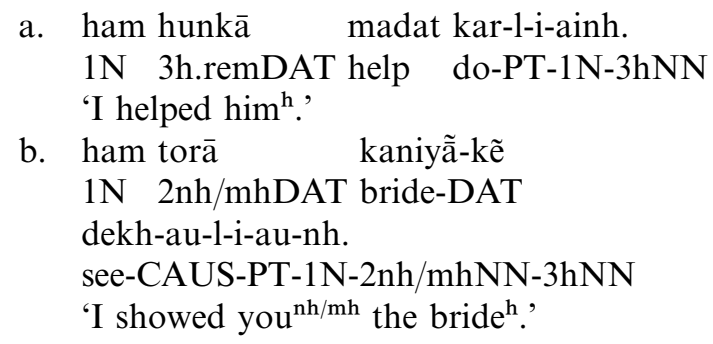

The verb in (20a) agrees with the subject ham and the object hunka $\bar{a}$. In (20b) the subject ham, the goal object torā, and the theme object kaniy $\tilde{a}$ all control distinct verb agreement. Notice that Maithili follows the principle of "differential object marking" (Bossong 1985) and encodes animate objects of monotransitive verbs in the same "dative" case that marks the recipient or goal argument of ditransitive verbs.

While double and triple agreement frequently encodes grammatical relations, this is not always the case. The second and third agreement markers in Agr2 and Agr3 can index referents in the wider discourse context:
a. ham okrā dekh-l-i-auk.
$1 \mathrm{~N}$ 3nh.remDAT see-PT-1-2nhNN
'I saw him $^{\text {nh }}$ (who is related to you ${ }^{\text {nh }}$, etc.)'
b. ham hinak betā-kẽ dekh-1-i-au-nh.
$1 \mathrm{~N}$ 3h.proxGEN son-DAT see-PT-1N-2nh/mhNN-3hNN
'I saw his ${ }^{\mathrm{h}}$ son (whom you ${ }^{\text {nh/mh }}$ referred to, etc.).'

We will come back to this phenomenon in section 3.3.

\subsection{Personal pronouns and nouns}

As mentioned above, verb agreement is sensitive to case marking on nominals. The better to understand this, we briefly compare the verbal system with the inflectional categories of nominals, first with pronouns, then with nouns. Like the agreement morphology, the pronouns of 
Maithili distinguish person, honorificity, proximity, and case. They are summarized in Table $4 .^{7}$

With regard to most categories, pronouns are equally or less differentiated than verbal inflections. They are less specific with regard to the "honorific" vs. "high-honorific" distinction among third persons, which are registered as -aith and -ath-inh, respectively, on the verb. In either case, the pronoun is $o$. Moreover, if third-person reference is proximate, all honorificity distinctions are neutralized to $i$. Among second persons, pronouns are as discriminatory as verb forms. However, the distinction between honorific ah $\tilde{a}$ and high-honorific apne is not encoded synthetically. It is therefore not included in the verb paradigm in Table 1. Rather, as noted earlier with regard to example (14), apne combines with a periphrastic construction involving the honorific degree marking auxiliary $j \bar{a}-\sim g e-$, (22a) (see also section 3.1). This contrasts with ah $\overline{\tilde{a}}$ - clauses, where the verb shows regular agreement, $(22 b)$.

(22) a. apne parh-al ge-1-aik.

2hhN read-P HON.AUX-PT-3

'You ${ }^{\text {hh }}$ were reading.'

b. ahã parh-ait cha-1-aũh.

$2 \mathrm{hN}$ read-IP AUX-PT- $2 \mathrm{hN}$

'You ${ }^{\mathrm{h}}$ were reading.'

Mid- and nonhonorific second-person pronouns are differentiated by $t \tilde{u}$ vs. tô, respectively, but this contrast is not always maintained. It is neutralized especially among lower-caste speakers (cf. example [59] below and the concluding section).

The distinction between honorific degrees is not limited to pronouns. Proper nouns, too, can be marked by an honorific (-ji) or a nonhonorific $(-y \bar{a},-b \bar{a},-m \bar{a})$ suffix, triggering corresponding verb inflection:

Table 4. Maithili personal pronouns

\begin{tabular}{llll}
\hline & Nominative & Dative & Genitive \\
\hline 1 & ham & hamrā & hamar \\
$2 \mathrm{nh}$ & tũ & torā & tohar \\
$2 \mathrm{mh}$ & tõ & torā & tohar \\
$2 \mathrm{~h}$ & ahã & ahã̃ẽ & ahãkẽ \\
2hh (indirect) & apne & apnekẽ & apnek \\
3nh proximate & $\mathrm{i}$ & ekrā & ekar \\
3nh remote & $\mathrm{u}$ & okrā & okar \\
3h/hh proximate & $\mathrm{i}$ & hinkāa & hinak \\
$3 \mathrm{~h} /$ hh remote & $\mathrm{o}$ & hunkā & hunak \\
\hline
\end{tabular}


(23)

a. Hari-ji bhajan gab-ait ch-aith.

H.-h religious.song sing-IP AUX-3hN

'Hari is is singing a bhajan.'

b. Hari-yā bhajan gab-ait ai-ch.

H.-nh religious.song sing-IP 3-AUX

'Hari ${ }^{\text {nh }}$ is singing a bhajan.'

Without such marking, a proper name has a neutral to mid-honorific value. Common nouns sometimes differentiate an honorific and a nonhonorific lexical form, such as bauā 'boy ', vs. chaura 'boy ${ }^{\mathrm{hh}}$, , or daiy $\bar{a}$ ' girl $^{\mathrm{h}}$ ' vs. chauri ' girl $^{\mathrm{nh}}$ ',

Both pronouns and nouns are more differentiated than verb agreement with regard to case. The verb morphology does not distinguish between different types of non-nominative. Another feature restricted to nominals is that of number. This category, however, is not fully grammaticalized with nominals either. It is expressed by the suffix -sabh or, with honorific reference only, the suffix -lokain (cf. Singh 1989: 88). Notice that -sabh also occurs as a free word in the sense of 'all', which attests to a low degree of grammaticalization (cf. Yadav 1996: 69). In verb agreement, no number distinctions are made. This fact, which makes Maithili quite different from other Indo-Aryan languages such as Hindi or Nepali, is the result of reanalyzing inherited number differentiation into honorificity distinctions - and it is these distinctions that we turn to in the following sections.

\section{FACE and EMPATHY}

In this section, we introduce two constraints, FACE and EMPATHY, which allow us to predict neutralization patterns in the nominative paradigm as well as the distribution of non-nominative agreement marking. We will first discuss some straightforward effects of FACE constraints on morphological structure (section 3.1) and then, in section 3.2, we will approach interactions between FACE and EMPATHY constraints in the formal structuring of intransitive and transitive verb agreement. Section 3.3 extends the analysis to nonargumental and triple agreement.

\subsection{Effects of FACE constraints}

Rational and cooperative behavior in human interaction entails, according to Brown and Levinson, the maintenance of FACE, which is defined as "the public self-image that every member wants to claim for himself" 
(1987 [1978]: 61). Since it is reasonable to expect that a person whose FACE is threatened will defend herself or himself by threatening other people's FACE, people share a common interest in maintaining each other's FACE. Brown and Levinson (1987 [1978]: 61) divide the concept of FACE into the following two related aspects:

(24) a. Negative FACE: the basic claim to territories, personal preserves, rights to nondistraction - i.e. freedom of action and freedom from imposition.

b. Positive FACE: the positive consistent self-image or "personality" (crucially including the desire that this self-image be appreciated and approved of ) claimed by interactants.

Both aspects of FACE can be maintained by a variety of strategies, each constituting acts of what is commonly called "politeness" or "modesty." In Maithili, there is a family of constraints as presented in (25), which explain a large part of Maithili verb agreement. The politeness strategies yielding these constraints are all based on "negative FACE."

(25) FACE CONSTRAINT:

a. Avoid uniquely identifying reference to the speaker.

b. Avoid uniquely identifying reference to the addressee if $s / h e$ has higher social status than yourself.

c. A third person with higher social status than another participant must be overtly marked.

The first constraint, (25a), reflects the speaker's aim of satisfying the hearer's negative FACE wants by means of self-effacement, which is a very efficient strategy to leave the hearer's need of freedom unimpeded. It is based on the first part of Brown and Levinson's strategy 7: "Impersonalize S[peaker] and H[earer]," which is "one way of indicating that S doesn't want to impinge on H" by phrasing "the FTA [facethreatening act] as if the agent were other than S, or at least possibly not S or not S alone" (Brown and Levinson 1987 [1978]: 190). An immediate effect of this is that there is no specific encoding of first persons in the verb-agreement system: first persons are always encoded by the same markers as honorific second persons, that is, by $-i$ [nonfuture] -aũh [past], or $-a$ [future]. This leaves forms like the following ambiguous:

(26) daur-1-aũh.

run-PT- $1 / 2 \mathrm{hN}$

'I ran' or 'You ${ }^{\mathrm{h}}$ ran.'

One can of course add the overt pronoun ham 'I' or ah $\tilde{\bar{a}}^{\text {'you }}$ ' to avoid ambiguity, but there is often no need for this in actual discourse and, indeed, it is precisely politeness that disfavors pronoun use here. 
By the same morphological neutralization as illustrated in (26), constraint (25b) is satisfied, too. This constraint can be derived from the second part of strategy 7 , according to which the face-threatening act has to be phrased as if "the addressee were other than $\mathrm{H}$, or only inclusive of H" (Brown and Levinson 1987 [1998]: 190). The case of Maithili is particularly remarkable, since the way in which the strategy of impersonalizing $\mathrm{S}$ and $\mathrm{H}$ is realized, viz. morphological neutralization, differs from all the respective constructions listed by Brown and Levinson (1987 [1978]: 190-206). In transitive forms, (25a) and (25b) are simultaneously active and have the effect that neither an honorific second person nor a first person can be clearly identified as specific participants. Instead, using the same neutralized morphemes as in intransitive forms, they are merely hinted at as both being involved in the same event. It is impossible to tell, therefore, whether the speaker saw the addressee or vice-versa in examples like the following.

(27) dekh-1-i.

see-PT- $1 / 2 \mathrm{~h}$

'I saw you ${ }^{\text {h, or 'You }}{ }^{\text {h }}$ saw me.'

Thus, Maithili here follows Brown and Levinson's strategy 7 by blurring the direction of the action between speaker and hearer, that is, by "disguising" what Heath (1991: 86) calls "doubly dangerous" scenarios since "they not only contain the most pragmatically sensitive pronominals" but "also combine them into a syntagmatic structure and thereby necessarily focus attention on the speaker-addressee relationship" (also cf. Heath 1998).

Another motivation for constraint (25b) is "point-of-view distancing," which is "speaking to the addressee as if the speaker (or the hearer) were not present" (Brown and Levinson 1987 [1978]: 201; cf. also 204-206). The most extreme case of hearer effacement is exhibited by the morphological makeup of high-honorific second person forms, (28a). Structurally, the forms are periphrastic third person formations built on the same auxiliary $j \bar{a}-\sim g e$ - as passives. They differ from true passives in that the agent noun phrase appears in the nominative rather than the ablative case, $(28 b)$.

(28) a. apne parh-al je-t-aik.

$2 \mathrm{hhN}$ read-P HON.AUX-FUT[3]-3

'You ${ }^{\text {hh }}$ will be reading.'

b. apne-sã i kitāb paṛh-al je-t-aik.

2hh-ABL this book read-P PASS.AUX-FUT[3]-3

'This book will be read by you ${ }^{\text {hh }}$.' 
The use of third-person forms for expressing honorific second person is a very common strategy to express honorificity and politeness and is well-attested in European languages such as German, Italian, and Polish. Whereas in European languages, the third-person forms are synchronically reanalyzed as honorific second-person forms, however, this does not seem to be true of Maithili. Using high-honorific second-person forms usually entails the speaker's avoidance of any glance at the highly respected hearer while using these forms, thus physically enacting a thirdperson situation. Typical situations of this are the taboo relations that prevail in traditional society between various "in-laws" of opposite sex and differing generation, for example between mother-in-law and son-inlaw (cf. Singh 1989). An alternative form that is used in such relations relies on a morphosyntactically elaborate passive - a very common strategy of hearer effacement (cf. Brown and Levinson 1987 [1978]: 194-196).

$$
\text { hunka-sã paṛh-al ge-l-ainh. }
$$

3h.remOBL-ABL read-P PASS.AUX-PT-3hNN

'You read it.' [lit. 'It was read by him.']

This form totally impersonalizes the hearer, even more so than the formation in (28) since no second-person pronoun (apne) is used at all. In either case, the ultimate target of the speech act is backgrounded and the speaker behaves as if he were talking to an intermediary, thereby directly indexing the complex "footing" of a taboo situation (cf. Goffman 1979; Levinson 1988).

Another consequence of constraint (25b) and point-of-view distancing becomes transparent when comparing the following two forms with (high-)honorific nominative agreement and second-person non-nominative agreement:

$$
\begin{array}{lll}
\text { (30) } & \text { a. } 3 \mathrm{~h} / \mathrm{hh} \rightarrow 2 \mathrm{nh} / 2 \mathrm{mh}: & \text {-ath-un }(h) \\
\text { b. } 3 \mathrm{hh} \rightarrow 2 \mathrm{~h}: & \text {-ath-in }(h)
\end{array}
$$

In these forms, the suffix -ath represents ' 3 hNominative'. The suffixes $-i n(h)$ and $-u n(h)$ represent different degrees of distance, $-i n(h)$ encoding a proximate, $-u n(h)$ a remote referent. The choice of the suffix -un $(h)$ for encoding the combined involvement of a nonhonorific or mid-honorific addressee and a (high-)honorific third person in the same event reflects the fact that this constellation represents the greatest possible social distance between participants. The addressee is of markedly lower social standing than the speaker and the third-person referent has a markedly higher standing. A typical situation would be as in the following 
example, where a high-caste speaker addresses the young son of a watchman:
(31) torā
ki kaha-1-ath-unh?
2nh/mhDAT what tell-PT-3hN-2nh $\leftrightarrow 3 \mathrm{~h}$
'What did he ${ }^{\text {h }}$ (e.g. the director) tell you ${ }^{\text {nh }}$ ?'

The form in (30b) above, -athinh, by contrast, involves scenarios of minimized social distance and therefore contains the proximate morpheme -inh. Both participants enjoy a similar (high-)honorific status.

Constraint (25c), finally, is based on the strategy "give deference" (Brown and Levinson 1987 [1978]: 178-187), which forms the basis of any linguistic system of honorifics. Like many such systems, however, Maithili honorifics also are "relation-acknowledging devices" (Matsumuto 1988) that go well beyond the redress of negative facethreatening acts. Use of special markers for honorific and high-honorific third persons is compulsory in any speech act, independent of the addressee's relation to it. This has many important effects for double and triple agreement, which we will discuss in section 2.5 . Here, we only mention one particular case. Wherever a referent of higher social standing is involved, this referent tends to trigger deictic agreement in the verb, thus maximizing the requirement of constraint given in $(25 \mathrm{c})$. Consider the following examples:

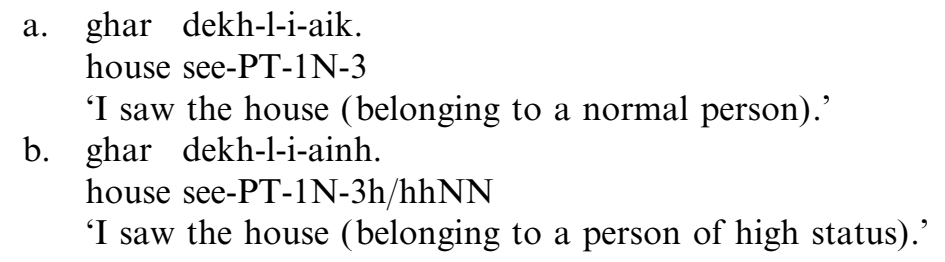

If the house is known to belong to a person of high status, this is generally marked. Not marking it usually implicates that the possessor of the house is of lower status.

Constraint (25c) is the only FACE constraint that requires rather than proscribes a certain marking. Thus, apart from third honorific persons, no person is required by the FACE-constraint family to trigger agreement. Within the nominative inflection paradigm, this is regulated, however, by a syntactic constraint that Maithili keeps in line with its IndoEuropean affiliation: the verb must agree with a nominative subject NP (cf. Bickel and Yadava 1998). As a result of this, all persons are registered, but, following (25a) and (25b), their identity is blurred in the case of first and second honorific persons. In contrast to nominative forms, there is no syntactic constraint in the non-nominative part of the conjugational 
paradigm. In this part, person inflection is governed exclusively by the FACE constraints together with, as we will see in the following sections, another pragmatically based constraint, EMPATHY.

\subsection{FACE constraints and EMPATHY}

In the preceding we saw how FACE constraints affect nominative agreement marking, resulting in formal neutralizations and particular ways of encoding scenarios. In this section we focus on patterns of a paradigmatic neutralization in non-nominative agreement. Whereas apart from the blending of $1 \rightarrow 2 \mathrm{~h}$ and $2 \mathrm{~h} \rightarrow 1$ scenarios, nominative participants are encoded by distinctive, uniquely identifying marking, the overt marking of non-nominative participants is highly restricted and not uniform across persons (see Table 1). For transitive verb forms, the following distribution holds:

(33) a. First and honorific second-person objects are not marked or, if the subject is also a first or honorific second person, are blended with the subject.

b. Second-person objects with nonhonorific or mid-honorific status are always registered.

c. Third-person objects are encoded only if the subject is a first or second person, but not if it is one of the third-person categories.

d. Third-person objects of high honorificity are marked only if the object is in focus or if the subject is a first, a second, or a nonhonorific third person.

This defines a hierarchy among person categories according to the number of transitive forms in which the object is overtly marked. Lowest in the hierarchy are those persons that never trigger non-nominative agreement, highest are those that always trigger agreement (cf. Williams 1973; Stump and Yadava 1988 for similar proposals):

(34) $2 \mathrm{nh} / 2 \mathrm{mh}>3 \mathrm{~h}$ focused $>3 \mathrm{~h}>3 \mathrm{nh}>1 / 2 \mathrm{~h}$

The same hierarchy, albeit in a simplified form, determines whether or not a referent is marked if it functions as the non-nominative single argument of an intransitive verb form, for example as in (16) and (17) above. First person, honorific second person, and nonhonorific third person do not trigger non-nominative agreement, whereas honorific third and non- or mid-honorific second persons do trigger agreement:

(35) $3 \mathrm{~h} / 2 \mathrm{nh} / 2 \mathrm{mh}>1 / 2 \mathrm{~h} / 3 \mathrm{nh}$ 
To some degree, both hierarchies are a product of the FACE-constraint family. Constraints (25a) and (25b) require downplaying and disguising of any involvement of a first person or of socially higher second persons so that they are not uniquely identifiable. Maithili abides with this pair of constraints, as we have seen before, by blurring the distinction between $1 \rightarrow 2 \mathrm{~h}$ and $2 \mathrm{~h} \rightarrow 1$ scenarios, or, in $3 \rightarrow 1$ and $3 \rightarrow 2 \mathrm{~h}$ scenarios, by leaving first and honorific second person objects unregistered in the agreement system (cf. Table 1). FACE constraint (25c) predicts that the involvement of third persons should be mentioned if they have higher social status than other participants and are therefore assigned the $3 \mathrm{~h}$ or $3 \mathrm{hh}$ honorific grade. This explains the higher position of $3 \mathrm{~h} / \mathrm{hh}$ as against nonhonorific 3 in the hierarchies in (34) and (35). It does not account, however, for the fact that even nonhonorific third person is marked in some transitive forms, for example in forms like (36a), and neither do the FACE constraints explain why non- and mid-honorific second-person forms are always marked, as illustrated by $(36 \mathrm{~b})$ :

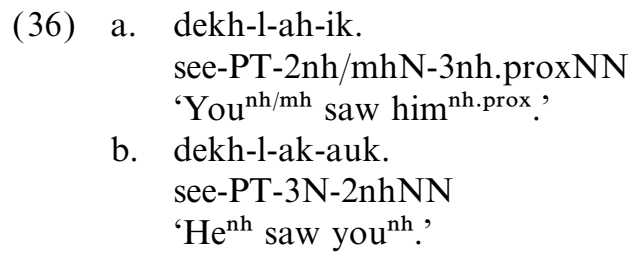

One aspect of this distribution, viz. the fact that second-person objects are more often marked in transitive forms than third persons, corresponds to a typologically well attested pattern. In many languages all around the globe, speech-act participants are better object agreement triggers than third persons. This has been noted for a large variety of languages by, among many others, Benveniste (1946), Silverstein (1976), Givón (1976) DeLancey (1981), Ebert (1987), van Driem (1992), and Bickel (1995).

In most cases, this difference in markedness between speech-act participants and third person can be directly accounted for as an iconic reflex of the fact that, in Benveniste's (1946) words, the third person is a "nonperson," characterized only negatively by its absence from the speech event. In Maithili, however, the marking distribution of objects is not a simple reflex of the status of the third person as a "nonperson." 8 Whether or not a nonhonorific third-person object triggers agreement depends on the whole transitive scenario; it is, in Silverstein's terms (1976), subject to a "global" rule of person indexing. Third-person objects, whether honorific, (37), or not, (38), are overtly marked if and only if the subject is a speech-act participant: 
(37) a. dekh-1-i-aik. see-PT- $1 / 2 \mathrm{hN}-3$

'I/you ${ }^{\text {h }}$ saw him/her ${ }^{\text {nh }}$.'

b. dekh-l-ak.

see-PT-3N

'He $\mathrm{H}^{\text {nh }}$ saw $\mathrm{me} / \mathrm{you}^{\mathrm{h}} / \mathrm{him} / \mathrm{her}^{\text {nh }}$.'

(38) a. dekh-1-i-ainh.

see-PT- $1 / 2 \mathrm{hN}-3 \mathrm{hNN}$

'I/you ${ }^{\mathrm{h}}$ saw him $/$ her $^{\mathrm{h}}$.'

b. dekh-1-aith.

see-PT-2hN

'He ${ }^{\mathrm{h}}$ saw him $/ \mathrm{her}^{\mathrm{nh} / \mathrm{h}}$.'

Thus, object marking seems to be more likely if a speech-act participant is involved in the scenario - irrespective of its role as subject, (36a), (37a), (38a), or as object, (36b). That is, object marking is more likely either if the object is itself a speech-act participant or if the subject is a speech-act participant. This directly reflects Kuno's notion (1987) of EMPATHY, which generally dominates grammatical roles:

(39) EMPATHY:

"EMPATHY is the speaker's identification, which may vary in degrees, with a person or thing that participates in the event or state that he describes in sentence" (Kuno 1987: 206).

Universally, speech-act participants have a higher degree of EMPATHY than third persons. The higher frequency of object agreement in Maithili transitive forms involving speech-act participants (as either subject or object) is thus a direct reflex of the higher degree of EMPATHY that obtains in these scenarios. High EMPATHY is not limited, however, to speech-act participants. Considerations of EMPATHY differences among third persons will complete our account of the distribution of non-nominative marking.

There is evidence that the high pragmatic prominence attached to focused third-person participants yields a high degree of EMPATHY in the event. In general, two different types of third-person referents can be said to differ in EMPATHY to the degree that their difference is treated by the grammar in a way similar to the difference between speech-act participants (SAP) and nonparticipants:

(40) SAP: non-SAP ::3rd person with high EMPATHY :3rd person with low EMPATHY

A clear effect of (40) can be found in indirect discourse. In this context, any increase in EMPATHY with embedded third-person pronoun 
referents assimilates these referents to speech-act participants, following the proportional equation in (40). Increasing the EMPATHY degree of a pronoun's referent can thus bring it in line and even suggest referential identity with a speech-act participant of the discourse being reported. This can be illustrated in English, as in many other languages, by the use of come verbs, a prime means to increase the EMPATHY degree of a third-person pronoun referent (cf. Kuno 1987: 224-227).

In English and many other languages, the verb to come induces a high degree of EMPATHY with the goal since the verb implies that the goal must be with the speaker. This has a direct effect on the possible coindexing in indirect discourse (Bickel 1991):

(41) a. $\mathrm{John}_{i}$ thinks that everybody should come to $\mathrm{him}_{i,{ }_{j}}$.

b. $\mathrm{John}_{i}$ thinks that everybody should $g o$ to $\mathrm{him}_{*, j}$.

The use of come in (41a) assigns high EMPATHY to the embedded thirdperson pronoun. Following the proportional equation in (40), the pronoun is therefore assimilated to the original speech act participant (John), and this functional assimilation in turn implicates coreference. The verb to go, by contrast, tends to imply that the goal is not with the speaker and therefore has a low degree of EMPATHY. As a result, the embedded pronoun is unlikely to be coindexed with the original speech-act participant in (41b).

In Maithili, focusing a third-person pronoun has a similar effect in indirect discourse: it increases EMPATHY and therefore the likelihood of coreference with the matrix subject whose speech or thought is reported in the embedded clause:

$$
\begin{aligned}
& \text { a. Rām-ji } i_{i} \text { soc-1-aith [je Hari-ji } \\
& \text { R.-h(N) think-PT-3hN COMP H.-h(N) } \\
& \text { hunkā/hunke }{ }_{i, 2 j} \quad \text { dekh-al-k-ainh]. } \\
& \text { 3h.remDAT/3h.remDAT:FOC see-PT-3N-3hNN } \\
& \text { 'Ram thought that Hari saw } \operatorname{him}^{\mathrm{h}} / \mathrm{HIM}^{\mathrm{h}} \text {.' } \\
& \text { b. Rām-ji i soc-1-aith [je Hari-ji } \\
& \text { R.-h(N) think-PT-3hN COMP H.-h(N) } \\
& \text { hunk } \bar{a}_{i, j} / * \text { hunke dekh-1-aith]. } \\
& \text { 3h.remDAT/3h.remDAT:FOC see-PT-3hN } \\
& \text { 'Ram thought that Hari saw him }{ }^{\text {h }} \text { ' }
\end{aligned}
$$

Focusing an object is marked by verb agreement (-ainh in [42a]) and optionally by raising the final vowel of the pronoun from /a/ to /e/ (hunke in [42a]; cf. Williams 1973: 367-369). Without agreement, a third-person object is out of focus and the corresponding pronoun does not support vowel-raising, (42b). 
This suggests that the difference between a focused and a nonfocused object pronoun is indeed parallel to the difference between a speech-act participant and a nonparticipant. Both distinctions are part of the EMPATHY hierarchy, which can be summarized for Maithili as follows:

$$
1 / 2>3 \text { focused }>3
$$

This now allows the formulation of a general EMPATHY-based constraint that predicts where non-nominative participants are registered by verb agreement and where they are left unmarked:

(44) EMPATHY CONSTRAINT:

Marked EMPATHY with a scenario, i.e. involvement of any participant higher than or equal to 3 focused in the hierarchy in (43), must be overtly signalled by selecting a verb form with explicit non-nominative agreement.

Above we observed that increased EMPATHY induces more object marking in transitive verb forms. Since the EMPATHY constraint is based on the hierarchy in (43), this can now be generalized to third persons, which explains why focused third-person objects obligatorily trigger agreement (cf. [45a] vs. [45b]) while non-focused third-person objects do not, (45c):

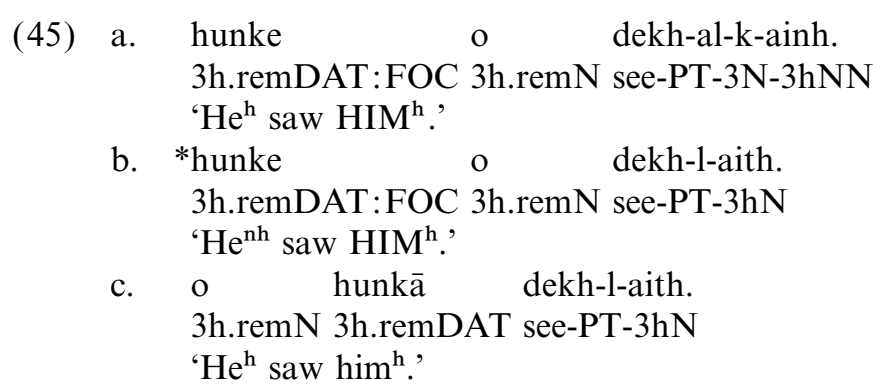

Let us summarize these findings. Two types of pragmatically motivated constraints are relevant for explaining which objects are overtly marked in a Maithili transitive verb: FACE and EMPATHY. The FACEconstraint family requires agreement marking according to the patterns spelled out in (25): first person and honorific second persons suppress marking whereas honorific third persons require marking. The EMPATHY constraints require marking if the referent has an increased degree of EMPATHY. This is the case with focused third persons and with speech-act participants. The two constraints come into conflict with first and honorific second persons: EMPATHY requires marking, FACE prohibits it. Following the logical design of optimality theory (Prince and Smolenky 1993; Archangeli and Langendoen 1997), we propose that, 
while these constraints are universal, they are ranked in language-specific, perhaps culture-dependent ways and that this ranking predicts which constraints can be violated under which condition. The agreement pattern described in Table 2 suggests that in Maithil discourse, FACE is valued higher than EMPATHY - a finding we will come back to in the concluding section:

\section{(46) FACE $>>$ EMPATHY}

Therefore, if there is a conflict, FACE overrides EMPATHY, that is, first- and honorific second-person objects are not marked. If there is no constraint conflict, either EMPATHY or FACE induces object agreement. This is summarized in Table 5, where a plus sign indicates that a constraint requires marking, a minus sign that a constraint suppresses marking. A zero signals that the corresponding constraint makes no prediction, that is, does not decide whether or not there should be object agreement. $\mathrm{N}$ stands for "nominative subject."

The distribution of plus, zero, and minus signs predicts in detail the marking of object agreement. Notice in particular that the marking of third-person objects is due to considerations of either FACE or EMPATHY or of both constraints simultaneously. This explains why 3 , $3 \mathrm{~h}$, and $3 \mathrm{~h}$ foc are not treated in the same way. Nonhonorific thirdperson objects are marked only if EMPATHY requires it, that is, if the nominative argument is a speech-act participant (see examples in [36] above). Honorific third persons, however, are marked because of EMPATHY or FACE: while their marking can be due to EMPATHY if there is a speech-act participant involved in the situation, that is, if $\mathrm{N}=1 / 2$, (47a) - it can also be triggered by considerations of FACE if the object has a higher social status than the subject, that is, if $3 \mathrm{nh} \rightarrow 3 \mathrm{~h}$, (47b). The impact of the FACE constraint is that a third-person object is marked if it has a higher social status than the subject, (47b), but not if both of them are equally marked as honorific (47c). ${ }^{9}$

Table 5. Face and empathy in object agreement

\begin{tabular}{llllll}
\hline & $2 \mathrm{nh} / \mathrm{mh}$ & 3h foc & 3h & 3 & $1 / 2 \mathrm{~h}$ \\
\hline FACE & $\phi$ & + & + & $\phi$ & - \\
EMPATHY & + & + & $\begin{array}{l}\phi \text { if } \mathrm{N}=3 \\
+ \text { if } \mathrm{N}=1 / 2\end{array}$ & $\begin{array}{c}\phi \text { if } \mathrm{N}=3 \\
+ \text { if } \mathrm{N}=1 / 2\end{array}$ & + \\
$\begin{array}{l}\text { Presence of } \\
\begin{array}{l}\text { object } \\
\text { marking? }\end{array}\end{array}$ & $\begin{array}{c}\text { yes, in all } \\
\text { scenarios }\end{array}$ & $\begin{array}{c}\text { yes, in all } \\
\text { scenarios }\end{array}$ & $\begin{array}{c}\text { yes if } \mathrm{N}=1 / 2 \\
\text { and in } \\
3 \mathrm{nh} \rightarrow 3 \mathrm{~h}\end{array}$ & yes if $\mathrm{N}=1 / 2$ & no \\
\hline
\end{tabular}




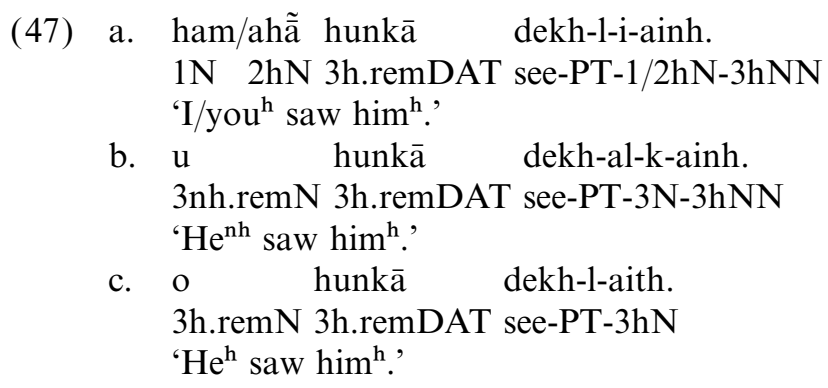

This is different from scenarios involving focused third persons. In this case, EMPATHY makes up for what is left unmarked by FACE: focused honorific third-person objects are marked even if there is no social cline between subject and object, (48), but they are left unmarked, as we saw in $(47 \mathrm{c})$, if they are out of focus.
(48) o hunkẽ dekh-al-k-ainh
3h.remN 3h.remDAT:FOC see-PT-3N-3hNN
'He $\mathrm{e}^{\mathrm{h}}$ saw HIM $^{\mathrm{h}}$.' ('It was him ${ }^{\mathrm{h}}$ who he ${ }^{\mathrm{h}}$ saw.')

As a result of this, focused honorific third-person objects are always marked and do not exhibit the partial marking distribution that is otherwise characteristic of third-person referents.

In Table 5 we assumed that the additional marking of honorific thirdperson objects in (47b) is due to the FACE-constraint family, in particular to its relation-acknowledging aspect underlying (25c). Alternatively, one might argue that this is again a case of EMPATHY because honorific third persons tend to be humans. Indeed, Maithili allows honorific thirdperson agreement only with human referents, however honored the referent may be. In order to signal the honorific status of a temple, for instance, a special copula is used, (49); inflecting the verb for honorific status is rejected:
a. mandir nik
thik.
temple beautiful HON:be:3:PRES
'The temple ${ }^{\mathrm{h}}$ is beautiful.'
b. maṇdir nik ai-ch (*ch-aith).
temple beautiful 3-be be-3hN
'The temple is beautiful.'

However, while necessary, the feature [+ human] is not a sufficient condition for the overall distribution of third-person marking - on two grounds: first, nonhonorific third persons are never marked, even if they are human. Second, reducing the conditions for third-person agreement 
to the feature [+human] does not explain why nonfocused honorific third-person objects are marked only if there is a social cline between subject and object (cf. [47b] vs. [47c]).

Table 5 explains the distribution of object marking in transitive verb forms. The same constraints with the same ranking (FACE $>>$ EMPATHY) also explain the distribution of non-nominative marking in intransitive verb forms. We saw above in (35) that non-nominative referents are marked if they are an honorific third person or a non- or midhonorific second person. This is predicted by the interplay between FACE and EMPATHY in Table 6.

Honorific third persons are marked because of FACE, non- and midhonorific second persons because of EMPATHY:
a. torā bhukh lag-l-auk.
2nh/mhDAT hunger be(come).perceptible-PT-2nhNN
'You ${ }^{\text {nh }}$ got hungry.'
b. hunkā bhukh lag-1-ainh.
3h.remDAT hunger be(come).perceptible-PT-3hNN
'He ${ }^{\mathrm{h}}$ got hungry.'

In case of conflict, that is, with first and honorific second persons, FACE again overrides EMPATHY, and the referent is not marked as such:
(51) a. hamrā bhukh lāga-1.
1DAT hunger be(come).perceptible-PT
'I got hungry.'
b. hamrā bhukh lāga-t.
1DAT hunger be(come).perceptible-FUT
'I will get hungry.'
c. hamrā bhukh laga-it
ai-ch.
1DAT hunger be(come).perceptible-IP $\phi$-AUX
'I get hungry' or 'I have appetite.'

The verb appears in the bare stem in the past tense, or reflects, in the future and present tense, nonreferential dummy agreement (" $\phi$ ", see section 2.1).

Table 6. Face and empathy in non-nominative single agreement

\begin{tabular}{lllll}
\hline & $2 \mathrm{nh} / \mathrm{mh}$ & $3 \mathrm{~h}$ & 3 & $1 / 2 \mathrm{~h}$ \\
\hline FACE & $\phi$ & + & $\phi$ & - \\
EMPATHY & + & $\phi$ & $\phi$ & + \\
$\therefore$ Presence of agreement marking? & yes & yes & no & no \\
\hline
\end{tabular}




\subsection{Nonargumental, deictic, and triple agreement}

We have so far concentrated on agreement with arguments of a predicate. In the speech community using the standard variety of Maithili, such agreement — single or composite — is normal and mandatory. But, as already illustrated by (2), there also exist cases of optional agreement with nonarguments. There are two conditions under which this occurs. First, agreement can be triggered by nonarguments if they function as nominals in a postpositional phrase or as possessor NPs. Second, the verb can register features of participants that are relevant for the event in a much broader sense. In this case, verb morphology does not "agree" with an NP in a narrow sense of the term but directly indexes referents in the discourse context. We follow Yadava (1996) in calling this phenomenon "deictic agreement," without precluding, though, that it could not be analyzed in parallel to what is sometimes called dativus (in)commodi, ethicus, or possessivus. The precise semantics of deictic agreement is not yet fully understood. It is, at any rate, immaterial for the following observations on the structuring of the paradigm.

Both nonargument and deictic agreement draw exclusively from the non-nominative set of markers, (52a); agreement markers from the nominative set must refer to syntactic arguments, $(52 \mathrm{~b})$ :

$$
\begin{aligned}
& \text { a. u bhāig je-t-auk. } \\
& \text { 3nh.remN run:CONV TELIC.AUX-FUT[3]-2nhNN } \\
& \text { 'He will run away (because he is afraid of you }{ }^{\text {nh }} \text { ).' } \\
& \text { b. *u bhāig je-t-æ. } \\
& \text { 3nh.remN run:CONV TELIC.AUX-FUT[3]-2nhN } \\
& \text { 'He will run away (because he is afraid of you }{ }^{\text {nh }} \text { ).' }
\end{aligned}
$$

The choice of whether or not a nonargumental referent can trigger optional agreement follows the same principles of FACE and EMPATHY that we found in the preceding section. However, nonargumental agreement always follows the principles of single agreement (Table 6) rather than those of double agreement (Table 5). Thus, only non- or mid-honorific second-person and honorific third-person referents can trigger nonargumental agreement. Apart from (52a), there are the following forms:

(53) a. u bhāig je-t-ah. 3nh.remN run:CONV TELIC.AUX-FUT[3]-2mhNN

'He will run away (because he is afraid of you ${ }^{\mathrm{mh}}$ ).'

b. u bhāig je-t-ainh.

3nh.remN run:CONV TELIC.AUX-FUT[3]-3hNN

'He will run away (because he is afraid of him ${ }^{\text {h }}$ ).' 
Agreement with a nonhonorific third-person nonargument is rejected, (54a), although the desinence -ahuk is morphologically well formed if used for argumental double agreement, (54b), following the logic of Table 5:

$$
\begin{aligned}
& \text { a. *tõ okare ghar par ge-1 } \\
& \text { 2mhN 3nh.remDAT:FOC house LOC go-P } \\
& \text { ch-al-ah-uk? } \\
& \text { AUX-PT-2mhN-3nh.remNN } \\
& \text { 'Had you been to his }{ }^{\text {nh }} \text { house?' } \\
& \text { b. tõ okrā a dekh-l-ah-uk. } \\
& \text { 2mhN 3nh.remDAT see-PT-2mhN-3nh.remNN } \\
& \text { 'Youm saw him }{ }^{\text {nh }} \text { (who is there).' }
\end{aligned}
$$

Notice that there is no general ban on double agreement with nonarguments. If licensed by the logic of Table 6, nonarguments can be marked by a second-position (Agr2) suffix:

(55) a. ham ohi ādam-sã bheț-1-i-ah.

$1 \mathrm{~N}$ that man-ABL meet-PT-1N-2mhNN

'I met that man (whom you ${ }^{\text {mh }}$ referred to).'

b. tõ dhyān lagā-kē

$2 \mathrm{mhN}$ attention perceptible:OBL-DAT

paṛh-1-ah-unh?

read-PT-2mhN-3h.remNN

'Did you ${ }^{\text {mh }}$ read attentively (for your ${ }^{\text {mh }}$ father ${ }^{\text {h }}$ 's sake)?'

In this case, even a third referent may be encoded (as long it satisfies the two-syllable constraint on verb agreement; see section 2.1):

(56) ham tohar bābu-ji-kẽ dekh-1-i-au-nh.

1N 2nh/mhGEN father-h-DAT see-PT-1N-2nh/mhNN-3hNN

'I saw your ${ }^{\text {nh/mh }}$ father.'

Although allowing double and triple agreement, nonargument marking follows, as we have seen above, the principles of single-agreement nonnominative marking in the decision on which argument can and which cannot trigger agreement. What is different from argumental single agreement, however, is that agreement with nonarguments is always optional and generally occurs only when the referent is in focus. With overt possessors or postposition-marked nominals, this is usually (but not necessarily) indicated by the focus suffix $-e$. Compare the focused possessor in (57a) with its nonfocused counterpart in (57b): 
(57)

a. ham tore ghar par ge-1

1N 2nh/mhGEN:FOC house LOC go-P

ch-al-i-ah.

AUX-PT-1N-2mhNN

'I had been to YOUR ${ }^{\text {nh/mh }}$ house (not somebody else's).'

b. ham tohar ghar par ge-1 ch-al-i.

1N 2nh/mhGEN house LOC go-P AUX-PT-1N

'I had been to YOUR ${ }^{\text {nh/mh }}$ house (not somebody else's).'

There is no such overt correlate in deictic agreement. If deemed worth mentioning, a bystander or any other referent in the discourse context can be indexed by verb agreement. Translation varies from possessor relations to elaborate conditioning: ${ }^{10}$

(58) a. tõ kitāb kin-1-ah-unh?

$2 \mathrm{mhN}$ book buy-PT-2mhN-3h.remNN

'Did you buy the book (for him $\left.{ }^{\mathrm{h}}\right)$ ?' or 'Did you buy $\left(\mathrm{his}^{\mathrm{h}}\right.$ ) book?'

b. ham okrā dekha-1-i-ah.

$1 \mathrm{~N} 3$ nh.remDAT see-PT-1N-2mhNN

'I saw him (who is related to you ${ }^{\mathrm{mh}}$ ).'

c. bhāig je-t-ainh.

run:CONV TELIC.AUX-FUT[3]-3hNN

' $\mathrm{He}^{\mathrm{nh}}$ will run away (because he is afraid of him ${ }^{\mathrm{h}}$ ).'

d. ham cail je-b-ah.

$1 \mathrm{M}$ move:CONV TELIC.AUX-FUT[1]-2mhNN

'I will go (if you ${ }^{\mathrm{mh}}$ don't want me to stay).'

The optional nature of deictic agreement suggests that both the FACE and the EMPATHY constraints can be overruled, presumably by a general constraint that limits agreement to verb arguments. The ranking between such a constraint and the FACE and EMPATHY constraints is variable in Maithili and left open to situation-specific determination.

\section{Conclusions}

The prime motivation for Maithili verb agreement is not so much to differentiate grammatical functions, but rather to index social relations, that is, relations of hierarchy (FACE) and relations of solidarity (EMPATHY). This is the reason why the verbal desinences are not tied to specific grammatical functions and can even, in the form of what Yadava (1996) calls "deictic agreement," encode referents that are not overtly present as NPs in the sentence. What matters is that a referent 
needs to be indexed because of FACE or EMPATHY. The grammatical role this referent has is of secondary importance. In line with this inherently social nature of the system, its origin (Jha 1958; Grierson 1909; Masica 1991) follows a pattern that is common in many languages around the world when developing honorific marking: erstwhile plural markers are reanalyzed as honorifics in repeated waves (in the case of, e.g., -ainh '3hNN' from a plural desinence; Grierson 1909: 119) and spatial demonstratives are cliticized to the verb (in the case of, e.g., -unh ' $2 \mathrm{nh} / \mathrm{mh} \leftrightarrow 3 \mathrm{~h} / \mathrm{hh}$ ' from a distal demonstrative). As an index of social relations, verb agreement has the important function of constantly recalling hierarchy and solidarity. There is no way of forming even the simplest sentence without paying attention to the relationship one has with the addressee and other persons that may relate in one way or the other to the situation expressed.

One aspect of these relationships is social hierarchy. Use of the Maithili agreement system implies that one closely observes issues of such hierarchies. It does not come as a surprise, therefore, that those people who are least interested in maintaining hierarchy, so-called lower-caste people, tend to reduce the system. High-caste speakers use nonhonorific and midhonorific forms (corresponding to the pronouns tũ and tõ) as indexes of people of lower status, whereas honorific (cf. pronoun ahã) and highhonorific (cf. apne) forms are used in order to honor or positively upgrade the addressee's social standing. Among uneducated lower-caste people, however, nonhonorific forms are generally used. In the following example from Singh (1989: 102), Mukund, a Harijan (untouchable), who has been abroad, is first taken as an educated Shastri and is thus addressed in the honorific form by his fellow Harijan people, until they discover that he is from the same village as they are. From that moment they address him with nonhonorific verb forms and the pronoun tõ which is used here in a sense that neutralizes the non- and mid-honorific distinction (cf. section 2.3 above):

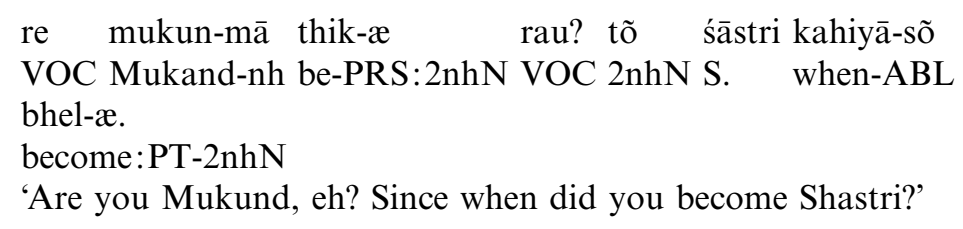

Another effect of system reduction is that low-caste speakers are found to reduce the very shape of the agreement system, for instance, when dropping final $/ \mathrm{h} /$ and $/ \mathrm{k} /$.

This is all in line with other systems of honorific marking around the world. In Maithili, however, there is another dimension of social relations 
that determines agreement: EMPATHY. EMPATHY comes into play only in the case that it is not outranked by FACE constraints. This kind of relationship between EMPATHY and FACE is not without precedent either and is typologically similar to the use of "pragmatic disguise" or "skewing" forms in many other languages (cf. Heath 1991, 1998) or of forms giving precedence to the addressee over the speaker (as in Algonquian) in order to prevent potentially "impolite" and socially delicate effects of the EMPATHY hierarchy (cf. Plank 1985). In Maithili such effects arise, above all, whenever the speaker is involved or when the addressee is of higher social standing that the speaker. It is exactly these participants who systematically defy non-nominative agreement or whose nature of involvement as subject or object is formally blurred and "disguised." In other cases, the effects of the EMPATHY hierarchy on verb agreement are unimpeded and sometimes, as in the case of $1 / 2 \rightarrow 3 \mathrm{~h}$ scenarios, even reinforced by FACE in that both constraints call for agreement simultaneously (see Table 5, section 3.2). If there is a conflict and thereby a forced choice, however, Maithili favors considerations of FACE over considerations of EMPATHY. Anecdotal observation of nonlinguistic behavior seems to support this finding, although this clearly calls for more detailed ethnographic research: there is, for example, a strong tendency in Maithili society to hide the expression of feelings that could trigger EMPATHY. If you experience problems or sorrow, good etiquette requires that you hide it as much as you can. If somebody of higher status blames you for a mistake, you are normally expected to accept the reproach, whether you find it justified or not. This is remarkably different from modern European or, even more so, modern American society, where such reproaches are easily bounced back. Such overt sorting-out of disagreement with higher-status people is considered rather rude behavior in Maithil society. Maintenance of FACE counts above all; discussing EMPATHY and affectedness comes second.

Received 5 August 1998

Revised version received 4 May 1999

\author{
University of California at Berkeley \\ and University of Zürich \\ Gutenberg University Mainz \\ Tribhuvan University and \\ Royal Nepal Academy Kāthmāndūu
}

\section{Notes}

* Research for this article was sponsored by grant No. Bi 591/1-2 of the Deutsche Forschungsgemeinschaft. Preliminary versions were presented at the 2 nd Project Meeting of the European Cooperation Project on Himalayan Languages in Paris, 
Appendix. Sample paradigms (past-tense forms)

Table A. Double-argument inflection of the transitive verb dekhab 'to see'

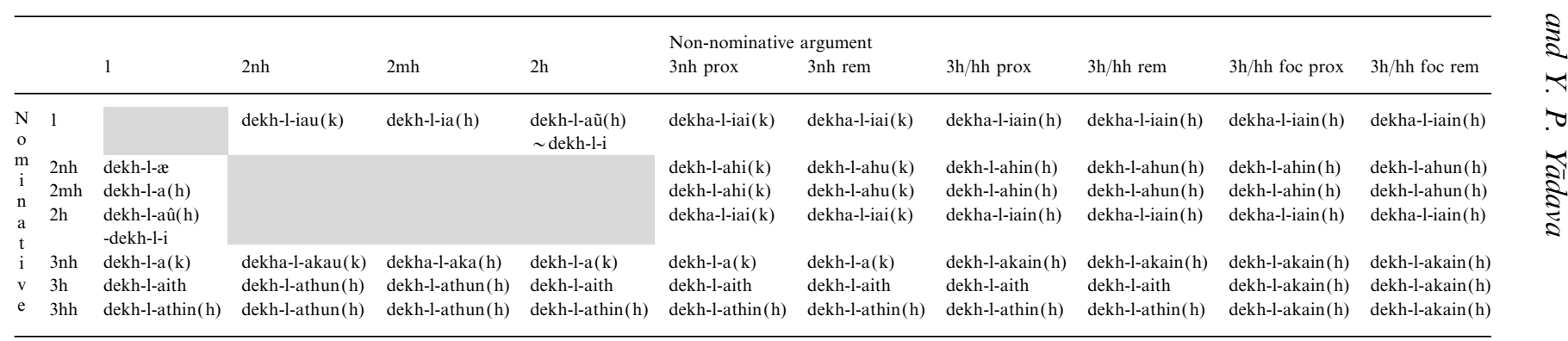


Table B. Nominative single agreement of daurab 'to run'

\begin{tabular}{ll}
\hline 1 & ham daur-l-ãu $(\mathrm{h}) \sim$ daur-l-i \\
$2 \mathrm{nh}$ & tũ dur-1-æ \\
$2 \mathrm{mh}$ & tõ daur-1-a $(\mathrm{h})$ \\
$2 \mathrm{~h}$ & ahã dur-1-ãu $(\mathrm{h}) \sim$ daur-1-i \\
$3 \mathrm{nh}$ & i/u daur-1-a $(\mathrm{k})$ \\
$3 \mathrm{~h}$ & i/o daur-1-aith \\
$3 \mathrm{hh}$ & i/o daur-1-aithin \\
\hline
\end{tabular}

Table C. Non-nominative singled agreement of lagab 'to feel'

\begin{tabular}{ll}
\hline 1 & hamrā lāga-l \\
$2 \mathrm{nh}$ & torā lag-l-au(k) \\
$2 \mathrm{mh}$ & torā lag-l-a(h) \\
$2 \mathrm{~h}$ & ahãkẽ lāga-l \\
$3 \mathrm{nh}$ & ekrā/okrā lāga-1 \\
$3 \mathrm{~h}$ & hinkāăhunkā lāg-l-ain(h) \\
$3 \mathrm{hh}$ & hinkā/hunkā lāg-l-ain(h) \\
\hline
\end{tabular}

13-15 November 1997, the International Seminar on Agreement at the University of Delhi, 8-11 January 1998, and the 19th Annual Conference of the Linguistic Society of Nepal, Kīrtipur, 26-27 November 1998. We thank these audiences and two anonymous reviewers for helpful comments. All errors are ours. Correspondence address: Prof. Dr Walter Bisang, Institut für Allgemeine und Vergleichende Sprachwissenschaft, Johannes-Gutenberg-Universität Mainz, Jakob-Welder-Weg 18, D-55099 Mainz, Germany. E-mail: wbisang@mail.uni-mainz.de.

1. We use the following abbreviations in interlinear glosses: AUX: auxiliary, CAUS: causative, CONV: converb, DAT: dative (marking animate objects of transitives and recipients of ditransitives), FUT: future, HON: (periphrastically marked) honorific degree, INVOL: involuntative (marking that the highest argument is in experiencer role), foc/FOC: focused, h: honorific, hh: high honorific, IP: imperfective participle, LOC: locative, mh: mid-honorific, nh: nonhonorific, N: nominative, NN: non-nominative, OBL: oblique case (used before postpositions), P: (aspectually neutral) participle, PASS: passive, PT: past, rem/REM: remote, VOC: vocative. An arrow $(\rightarrow$ indicates a scenario with a nominative (left) and non-nominative (right) participant, a double arrow $(\leftrightarrow)$ signals involvement of two participants in either case role. Square brackets enclose selectional restrictions of a morpheme. Notice that number is not fully grammaticalized in Maithili. To facilitate glossing, however, we translate always by singular number, even though the plural would be equally appropriate in most cases.

Maithili is transliterated following Indological tradition but CV sequences are metathesized according to the modern spoken language, whence we write pāin for orthographic pāni 'water'. Also, we consistently note the distinction between $/ \mathfrak{x} /$ and /ai/ (phonetically [əj]) that is blurred in the native devanāgari orthography. Notice that what is written as $\langle\bar{a}\rangle$ vs. $\langle\mathrm{a}\rangle$ is phonetically a difference of quality, viz. [a] vs. [ə] rather than length. There are morphophonological processes of compensatory lengthening, however, suggesting that the quantitative interpretation of the opposition is still 
relevant in underlying structure (see section 2.1). We do not transliterate, however, the by-now obsolete length distinctions of $\langle\overline{1}\rangle:\langle i \mathrm{i}\rangle$ and $\langle\overline{\mathrm{u}}\rangle:\langle\mathrm{u}\rangle$.

2. Yadav (1996: 185) claims that the object of a postposition cannot trigger agreement. Our consultants accept examples like (2a) without hesitation, but we cannot exclude the possibility of dialect variation. The agreement paradigm is subject to substantial synchronic and diachronic variation, as attested by the work of Grierson (1909), Jha (1958), Williams (1973), Stump and Yadava (1988), and others. The difference from the material in Yadav's (1996) recent reference grammar is that his -ahũ is the written form of regularly metathized -aũh; $-e$ and - $a i k$ are dialect variants of $-\alpha$ and $-a k$, respectively.

Notice further that examples like (2c) are difficult to reconcile with the very notion of "agreement" since the second-person suffix - ah does not agree with any nominal in the clause. In spite of this we continue traditional parlance for convenience. We intend the term "agreement" in a very loose sense, as an equivalent of "person marking on the verb." For discussion of the theoretical implications of examples like (2c) and parallels in other languages, see Bickel (1997, i.p.).

3. Notice, however, that multiple agreement is attested for the northern languages Sindhī, Kāśmīrīi, Lahṇ̣̣ā, and Kurmālīi see Grierson (1895) and Masica (1991).

4. Note that an alternative explanation in terms of Addis's (1993) information-based paradigm-trimming principles would not work here: *-ak-ain-hunh would refer to a scenario with third person only, viz. $3 \mathrm{nh}$ nominative and two $3 \mathrm{~h}$ participants in theme and goal role. Addis's constraint against "marking overload" does not preclude thirdperson triple-agreement forms, which indeed are well formed in many other languages.

5. In contrast to many other Indo-Aryan languages, Maithili has no ergative case marking.

6. This finding violates, incidentally, Lehmann's (1988: 58) principle that "what can agree in case never agrees in person, and vice-versa"; also cf. Bickel and Yadava (1998).

7. The oblique forms of pronouns, which are used before postpositions, are morphologically identical to the dative except for honorific and high-honorific second-person pronouns, where the oblique forms resemble nominatives.

8. An additional problem for an iconicity-based account is that with third-person proximate objects (ending in -ik if nonhonorific and -inh if honorific), the referent must be present at the location of the speech event, even though s/he does not directly participate in it.

9. The FACE constraint applies vacuously to scenarios in which the subject is honorific ("h") and the object high-honorific ("hh") because there is simply no morphological means to mark the difference between a $3 \mathrm{~h} \rightarrow 3 \mathrm{hh}$ and a $3 \mathrm{hh} \rightarrow 3 \mathrm{~h}$ scenario on the verb.

10. Examples like (58b)-(58d) clearly dispell any attempt to explain deictic agreement as instances of "possessor raising," a hypothesis that one might entertain on the basis of (58a) compared to (57a). See Stump and Yadava (1988) for further argumentation against possessor raising in Maithili.

\section{References}

Addis, Kirstin (1993). Paradigm trimming in Basque. Linguistics 31, 431-474.

Archangeli, Diana; and Langendoen, D. Terence (eds.) (1997). Optimality Theory: An Overview. Malden, MA: Blackwell.

Benveniste, Émile (1946). Structure des relations de personne dans le verbe. Bulletin de la Société de Linguistique de Paris 43. (Reprinted in Benveniste, Émile [1966]. Problèmes de linguistique générale 1, 225-236. Paris: Gallimard.) 
Bickel, Balthasar (1991). Die Wandlungen räumlicher Inversion. Unpublished manuscript, University of Zürich.

- (1995). In the vestibule of meaning: transitivity inversion as a morphological phenomenon. Studies in Language 19, 73-127.

-(1997). Double-marking languages and morphosyntactic typology. Paper presented at the 2nd Conference of the Association for Linguistic Typology, Eugene, September 11-14.

-(i.p.). Hidden syntax in Belhare. In Himalayan Linguistics, George van Driem (ed.). Berlin: Mouton de Gruyter.

-; and Yādava, Yogendra, P. (1998). A fresh look at grammatical relations in Indo-Aryan languages. Paper presented at the 4th Himalayan Languages Symposium, Pune, December 8. (Unpublished manuscript, University of California, Berkeley, and Royal Nepal Academy, Kāṭhmāṇụū.)

Bossong, Georg (1985). Empirische Universalienforschung: differentiale Objektmarkierung in neuiranischen Sprachen. Tübingen: Narr.

Brown, Penelope; and Levinson, Stephen C. (1987 [1978]). Politeness: Some Universals in Language Use. Cambridge: Cambridge University Press.

DeLancey, Scott (1981). An interpretation of split ergativity and related patterns. Language $57,626-657$

Dixon, Robert M. W. (1994). Ergativity. Cambridge: Cambridge University Press.

Ebert, Karen H. (1987). Grammatical marking of speech act participants. Journal of Pragmatics 11, 473-482.

Givón, Talmy (1976). Topic, pronoun, and grammatical agreement. In Subject and Topic, Charles N. Li (ed.), 149-188. New York: Academic Press.

Goffman, Erving (1979). Footing. Semiotica 25, 1-29.

Grierson, George A. (1895). On the pronominal suffixes of the Kāçmīī language. Journal of the Asiatic Society of Bengal 64, 336-351.

-(1909). An Introduction to the Maithilī Dialect of the Bihārì Language as Spoken in North Bihār, 2nd ed. Calcutta: Asiatic Society of Bengal.

Heath, Jeffrey (1991). Pragmatic disguise in pronominal-affix paradigms. In Paradigms: The Economy of Inflection. Frans Plank (ed.), 75-89. Berlin: Mouton de Gruyter.

- (1998). Pragmatic skewing in $1 \leftrightarrow 2$ pronominal combinations in Native American languages. International Journal of American Linguistics 64, 83-104.

Jha, Subhadra [=Subhadrā Jhā] (1940). Maithili phonetics. Indian Linguistics 8, 435-459.

- (1958). The Formation of the Maithili Language. London: Luzac.

Kuno, Susumu (1987). Functional Syntax: Anaphora, Discourse and Empathy. Chicago: University of Chicago Press.

Lehmann, Christian (1988). On the function of agreement. In Agreement in Natural Language, Michael Barlow and Charles A. Ferguson (eds.), 55-65. Stanford: CSLI.

Levinson, Stephen C. (1987). Pragmatics and the grammar of anaphora. Journal of Linguistics 23, 379-434.

- (1988). Putting linguistics on a proper footing: explorations in Goffman's concept of participation. In Erving Goffman: Exploring the Interaction Order, Paul Drew and Anthony Wootton (eds.), 161-227. Cambridge: Polity.

- (1991). Pragmatic reduction of the binding conditions revisited. Journal of Linguistics 27, 107-161.

Masica, Colin P. (1991). The Indo-Aryan Languages. Cambridge: Cambridge University Press.

Matsumoto, Yoshiko (1988). Reexamination of the universality of face: politeness phenomena in Japanese. Journal of Pragmatics 12, 403-426.

Plank, Frans (1985). Die Ordnung der Personen. Folia Linguistica 19, 111-176. 
-(1991). Rasmus Rask's dilemma. In Paradigms: The Economy of Inflection, Frans Plank (ed.), 161-196. Berlin: Mouton de Gruyter.

Prince, Alan; and Smolensky, Paul (1993). Optimality Theory. Technical Report 2. New Brunswick, NJ: Rutgers University Center for Cognitive Science.

Silverstein, Michael (1976). Hierarchy of features and ergativity. In Grammatical Categories in Australian Languages, Robert M. W. Dixon (ed.), 112-171. Atlantic Highlands, NJ: Humanities.

Singh, Udaya Narayana [=Udayanārāyaṇa Singh] (1989). How to honor someone in Maithili. International Journal of the Sociology of Language 75, 87-107.

Stump, Gregory T.; and Yadav, Ramawatar (1988). Maithili verb agreement and the control agreement principle. In Papers from the 24th Annual Regional Meeting of the Chicago Linguistic Society, Part 2: Parassession on Agreement in Grammatical Theory, 304-321. Chicago: CLS.

Van Driem, George (1992). Le proto-kiranti revisité: morphologie verbale du lohorung. Acta Linguistica Hafniensia 24, 33-75.

Van Valin, Robert D., Jr. (1995). Towards a functionalist account of so-called extraction constraints. In Complex Structures: A Functionalist Perspective, Betty Devriendt, Louis Goossens, and Johan van der Auwera (eds.), 29-60. Berlin: Mouton de Gruyter.

Williams, J. (1973). Clause patterns in Maithili. In Patterns in Clause, Sentence, and Discourse in Selected Languages of India and Nepal, Part 2, 345-422. Ron L. Trail (ed.). Kathmandu: Tribhuvan University Press.

Yadav, Ramawatar (1996). A Reference Grammar of Maithili. Berlin: Mouton de Gruyter.

Yadava, Yogendra P. [=Yogendraprasād Yādava] (1996). Verb agreement in Maithili. Journal of Nepalese Studies 1, 109-121. 